\title{
Impact of Family Domain on Work-Life Balance of Professional Working Mothers
}

\author{
Sushma Manandhar ${ }^{1}$
}

\begin{abstract}
The paper aims to provide empirical evidence on impact of family domain (family support and spouse support) on work-life balance of full time professional working mothers in telecommunication and academic sectors. The structured questionnaire was administered among 90 working mothers representing from both sectors in Kathmandu Valley. The study followed descriptive and analytical research design. Correlation and regression analyses were carried on to test the proposed hypotheses. The statistically significant positive impact of family support and spouse support was found on work life balance of professional working mothers under the study. family support and spouse support enhance the professional working mothers to become highly committed to their job or work devoting considerable time and effort to their career role and work-life balance.
\end{abstract}

Key words: Professional working mothers, Work-life balance, Family and spouse support

\section{INTRODUCTION}

Clark (2000) has defined work-life balance as satisfaction and good functioning at work and at home with a minimum of role conflict. It is the meaningful achievement and enjoyment in everyday life. Finding work-life balance in today's frenetically paced world is no simpler task. Spending more time at work than at home means missing out on a rewarding personal life. Then again, due to challenges in personal life, such as caring of an aging parent or coping with marital problems, concentrating on job has become difficult.

The erosion of the gender division of labor itself is the main source of work-family conflict (Loscocco, 2000). Though it is not surprising that traditional gender roles assumed that men were primarily responsible for family financial support, while women were responsible for childcare and household duties; what is startling is that such taboos or views are still prevalent today. The gender stereotypes appeared to be the cause of many of the barriers women face in their work settings. So, for women, domestic

1. Mrs. Manandhar is Lecturer at Public Youth Campus, Tribhuvan University,

Email: manandharsushma@gmail.com 
responsibilities were more likely to curtail their hours at work and long working hours often increased the pressure on work for them. Working mothers refers to women who are mothers and work outside the home for income in addition to the work they perform at home in raising their children.

Balancing work and family is often more difficult for women than for men because of the disproportionate burden of the family responsibilities (Bird, 2006). Women face uneven distribution of childcare and other domestic responsibilities, which become major barriers in the advancement of their career (Cross and Linehan, 2006). But Yadav and Dabhade (2013) concluded that the women working in all types of professions demonstrating that there are no gender differences in work. According to them the increasing demands at work place, the interface between work-life and personal life needs more attention and leads to stress and such situation affect person's health both physiologically and psychologically.

Now a day, the working mothers are continuously struggling to find the balance needed to deal and handle the demands of both work life and home life (Backett-Milburn et al., 2008); (Perrakis \& Martinez, 2012). Furthermore, given the increasing pressure and demands placed on working mothers, balancing a work and a personal life is very challenging and stressful for many women. To balance job demands and household tasks, including household and childcare demands, has been documented as a huge barrier that prevents women from achieving work-life balance. Mani (2013) explored the major factors which influenced the work-life balance of women professionals in India such as role conflict, lack of recognition, organizational politics, gender discrimination, and elderly and children care issues, quality of health, problems in time management and lack of proper social support. Crowley and Kolenikov (2014) revealed that mothers with partners experienced less stress at home and work. According to them the mothers who had control over their time-off was significant and relevant to their perceptions of work and parenting demands.

Family support: Social support is a multidimensional construct and defined as the comfort, assistance, and/or information one receives through formal or informal social contacts (Wallston et. al., 1983). It comes from immediate family, friends, and neighbors and provide stability and backup when an employee is dealing with the everyday demands of raising a family, caring for a sick or dying family member, starting or maintaining a personal relationship, taking courses, engaging in physical activity, or contributing to the community. Mehta (2012) concluded that the female employees face the problem of balancing personal and family life and more imbalances was found in married women due to more family responsibilities. According to Shiva (2013), the working women having small children are forced to leave their child in daycare or in hands of maid and creates more tension and less concentrate on their work and also unable to give the time as required. Rosenbaum and Cohen (1999) studied among 94 married Israeli mothers (ages 23-40) as full-time outside employees and revealed that women who had at least one resource (resourcefulness or spousal support) were less distressed than women who did not have either of these resources. Manandhar (2010) also found positive association of work-life balance between social supports from family in Nepalese hospital sector. 
Spouse support: Spouse means a husband or wife, considered in relation to their partner. Working hours devoted by spouses may indicate the degree of importance that working has to their career attainment. Most of the past researches showed that working spouses might be expected to experience more work-family conflict than those who are not working (Harlan \& Weiss, 1980; Greenhauset al., 1989). The positive relationship between working spouse and work life balance indicates that the spouses of respondents were more supportive. Shrestha (2009) found that there was no significant effect of spouse support on job satisfaction, but the spouse support was highly associated with family satisfaction only among women. Madipelli, et al. (2013) studied work-life imbalance and concluded that marital relationship, attitude and cooperation of husband and family members also related to work-life balance of midlife working women in the academic field. Ferguson et al., (2016) also found that as spousal support increased, relationship tension decreased. This pattern was stronger for work-linked couples. In this backdrop the objectives of the study are to

- examine the impact of family domain (family support) on work-life balance of professional working mothers.

- examine the impact of family domain (spouse support) on work-life balance of professional working mothers.

\section{RESEARCH METHODOLOGY}

The study followed descriptive research design. Questionnaire survey was used for the collection of primary data. The study considered top 5 telecommunication organizations of Nepal, 10 universities of Nepal and 162 secondary schools in Kathmandu as its population. Among them 1 telecommunication from telecommunication sector and 1 university and 5 secondary schools from academic sector were selected as samples. The survey was conducted during July 2017. Total 100 questionnaires were distributed to full time employees of sample organizations. Total 90 responses were collected in which 33 respondents were from telecommunication sector and remaining 57 respondents were from academic (university: 20 and secondary schools: 37 ) sector. Cronbach's alpha was used to test the reliability of the data and has been reported in table 2 . The relationships among the variables are shown in the following framework in figure 1.

\section{CONCEPTUAL FRAMEWORK}

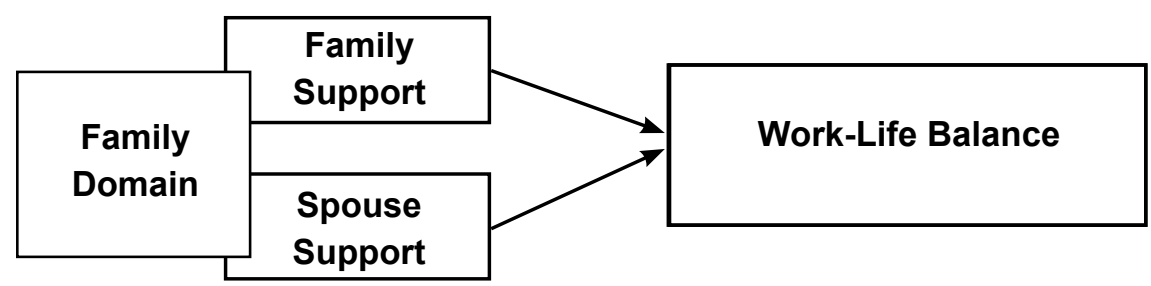

Figure 1: An Impact of Family Domain (FS and SS) on Work-Life Balance of Professional Working Mothers 
The variables under the study are work-life balance (WLB) and family domain (family support: FS and spouse support: SS). The dependent variable WLB explains the balancing time both for work and family. Similarly, independent variables FS and SS explain family members and spouse supports on household and childcare activities respectively.

The correlation and regression analyses were also carried on to test the hypotheses. The following hypothesis is tested in the study:

Hypothesis 1 : Family domain (family support) positively contributes to work-life balance of professional working mothers.

Hypothesis 2 : Family domain (spouse Support) positively contributes to work-life balance of professional working mothers.

\section{PRESENTATION AND ANALYSIS OF DATA}

Descriptive Analysis: The following table 1 represents profile of 90 respondents, in which 40 and 26 respondents were lies between age 30-40 years and 40-50 years respectively. Only 6 respondents were below 30 years and 18 respondents were age above 50 years was found. The total respondents had 137 children and 34, 26 and 22 respondents have children above 10 years, 5-10 years and below 5 years respectively. Only 2 and 6 respondents have children below 5 and above 10 years, and $5-10$ and above 10 years respectively.

Table 1: Profile of Professional Working Mothers

\begin{tabular}{|c|c|c|c|c|}
\hline \multirow{2}{*}{ SN } & \multicolumn{2}{|c|}{ Age of Respondents } & \multicolumn{2}{|c|}{ Age status of Children } \\
\hline & Age & Respondents & Age & Respondents \\
\hline 1 & Below 30 years & 6 & Below 5 years & 22 \\
\hline 2 & $30-40$ years & 40 & $5-10$ years & 26 \\
\hline 3 & $40-50$ years & 26 & Above 10 years & 34 \\
\hline 4 & Above 50 years & 18 & Below 5 and Above 10 years & 2 \\
\hline \multirow[t]{2}{*}{5} & & & $5-10$ and Above 10 years & 6 \\
\hline & & 90 & Total & 90 \\
\hline
\end{tabular}

*These estimates are based on 90 responses.

Source: survey 2017

Table 2 presents the mean values from telecommunication and academic sectors on the given variables FS, SS and WLB. The Mean values are ranked from highest to lowest mean under the variables. SD is standard deviation and $\mathrm{N}$ indicates total number of respondents. Cronbach's Alpha measures for reliability test. 
Table 2: Descriptive Analysis

\begin{tabular}{clccccc}
\hline SN & \multicolumn{1}{c}{ Variables } & Mean & Rank & SD & N & Cronbatch Alpha \\
\hline 1 & Family Support (FS) & 4.36 & 1 & 0.587 & 90 & \\
2 & Spouse Support (SS) & 4.16 & 2 & 0.634 & 90 & 0.848 \\
3 & Work- Life Balance (WLB) & 4.14 & 3 & 0.646 & 90 & \\
\hline
\end{tabular}

*These estimates are based on 90 responses.

Source: survey 2017

Table 2 presents the different mean values under the observations of variables. The highest to lowest mean values were found in the given statements of the variable FS, SS and WLB were $4.36,4.16$ and 4.14 respectively. Likewise, the standard deviation shows the deviation from the average condition of respondents. The less deviation was found in the statement of variable FS (0.587).In the variables, WLB and SS the more deviations 0.646 and 0.634 were found respectively. The Cronbach's alpha coefficient 0.848 shows the higher internal consistency of the variables under the study. The study describes that the professional working mothers have more supports from their family members and spouse on household and childcare activities respectively. They also agreed on equal balancing of time for their work and family. The study supports to Frone et al. (1997). They concluded that family related support (spouse and other family members) might reduce family to work conflict by reducing family distress and parental overload. Allen (2001) also found that a variety of occupations, employees who perceived their organizations as less family-supportive experienced more work-family conflict, less job satisfaction, less organizational commitment, and greater turnover intentions than those who perceived their organizations as more family-supportive.

Relationship between FS and WLB, SS and WLB: The correlation analysis is used to find out the correlation between observable variables FS and WLB, and SS and WLB.

Table 3: Pearson correlation coefficient between dependent and independent variables

\begin{tabular}{cccc}
\hline \multirow{2}{*}{ SN } & Dependent Variable & \multicolumn{2}{c}{ Independent Variables } \\
\cline { 3 - 4 } & WLB & FS & SS \\
\hline 1 & WL.664 & $0.630^{\star *}$ \\
\hline
\end{tabular}

$\left.{ }^{*}\right)$ significance at $5 \%$ level and $\left({ }^{* *}\right)$ significance at $1 \%$ level

Table 3 has shown the correlation results between observable variables. It explains the statistically significant positive association between WLB and FS (coefficient: 0.664 ) at $1 \%$ level of significance. Likewise, the correlation was also statistically significant (coefficient: 0.630 ) at 1 percent level between WLB and SS. The study supports the hypothesis. Tamang (2008) also found positive relationship between work-life balance and social support in the Nepalese hospitality industry. Haslam et al. (2015) reports findings on the challenges working mothers endure and what they consider as their main support systems. They concluded that not having enough personal time due to the 
long list of duties on their daily routine, which in the end had negative effects on their relationship with their families, especially their children and spouses.

Effect of FS and SS on WLB: The regression is used to observe relationship between the variables and to test the proposed hypothesis. The following models are developed to study the effect of dependent and independent variables:

Models:

$W L B=f(F S)$

$W L B=f(S S)$

Dependent variable: WLB

Independent variable: FS and SS

Table 4: Impact of Family support and spouse support on work life balance

\begin{tabular}{c|c|c|c|c|c|c}
\hline Models & Constant & FScoefficient & SScoefficient & $\mathbf{R}^{\mathbf{2}}$ & F-stat & Sig \\
\hline WLB =f (FS) & 0.962 & - & - & 0.441 & 69.288 & .000 \\
WLB = f (SS) & 1.479 & -.731 & 0.641 & 0.397 & 57.946 & .000 \\
\hline
\end{tabular}

The table 4 has presented statistically significant positive effect of FS on WLB (coefficient: 0.731 ) at 5 percent level. The same impact of SS was also found on WLB (coefficient: 0.641$)$. The values $0.441(44.1 \%)$ and 0.397 (39.7\%) of the total variance of dependent variable WLB are explained by independent variables FS and SS respectively. The independent variable SS has shown minimum impact on WLB as compare with impact of independent variable FS on WLB. The F-statistic of the models shows the test of goodness of fit. The results matched with the hypothesis. The study found the significant positive impact of family support and spouse support on work-life balance of professional working mothers. Similarly, According to Admans et al., (1996) social support from family as being a subject of great importance in reducing work-family conflict. Carlson and Perrwe, (1999), and Greenhaus and Parasuraman, (1994) also found a positive impact of spouses support on work-family balance by reducing work-family conflict.

\section{FINDINGS, CONCLUSION AND RECOMMENDATIONS}

The study found significant positive impact of family support and spouse support on work-life balance of professional working mothers working in both telecommunication and academic sectors within Kathmandu valley. The study found a significant positive impact of FS on WLB (coefficient: 0.731) and SS on WLB (coefficient: 0.641) at 5 percent level. The study concluded that the professional working mothers have more support from their family members and spouse on household and childcare activities respectively. The study also found statistically significant positive correlation of WLB in FS (0.664) and SS (0.630) at 1 percent level. Vani and Nagajothi (2015) also revealed that the women could able to balance their personal and professional works with help of family and husband support. 
The study only limits to the variables taken under the study. So it concluded that the family and spouse supports to working mothers on household and childcare activities are positively contributed to work-life balance respectively in the both sectors. But in both job and life aspects there is evidence that women experience less progression, engage in short-term promotion plans rather long-term goals, pursue career strategies focused on individual learning and growth than organizational rewards and bear greater family responsibilities and work-family conflict than their male counterpart. So, it is a high time provide social support from own home (family and spouse support) to professional working mothers. Such types of supports enhance to feel empowered by working mothers to balance work and family life.

Adhikari (2009) stated that the role of human resource management is to create a good working environment by inspiring people at work. So, some of the strategies and skills at work such as planning, organizing and setting limits must utilize at home and work place to balance both work and family life. As the working mothers who succeed to achieve it through their strategies also must be followed by future generation. On other hand, organizations also need to adopt human resource strategies and policies to overcome the issues of the work-life balance of women in the current business environment.

In Nepalese context, considering the nation wide circumstances, the concept of women empowerment is still nascent. However with changing times, the problems for working mother will indeed prove to be critical. With increasing trend of women involvement in developed cities, this will no doubt erupt as a phenomenal challenge to everyone wishing for progressive development of the society. Henceforth it becomes responsibility of every understanding citizen of the country to support aspiring women workforce so that the society and the nation as a whole can march its way towards prosperity.

Finally, the information provided from this study also impacts social change by increasing the awareness around the need to support mothers who may struggle to find balance between work and life. The future working mothers can better understand how to balance work and family life by investigating the challenges women face, the strategies they implement, and the support systems they utilize.

\section{REFERENCE}

Adams, G., King, L., \& King, D.W. (1996). Relationships of job and family involvement, family social support, and work-family conflict with job and life satisfaction. Journal of Applied Psychology, 81(4), 411-420.

Adhikari, D. R. (2009). Human Resource Management $\left(4^{\text {th }}\right.$ ed). Kathmandu, Nepal: Buddha Academic Publishers and Distributers Pvt. Ltd.

Allen, T.D. (2001). Family-supportive work environment: The role of organizational perceptions. Journal of Vocational Behavior, 58(3), 414-435.

Backett-Milburn, K., Airey, L., McKie, L., \& Hogg, G. (2008). Family comes first or open all hours? How low paid women working in food retailing manage webs of obligation at home and work. Sociological Review, 56(3), 474-496.

Bird, S.R. (2006). Theorizing masculinities: recent trends in the social sciences. Gender Studies Journal of Eastern Europe, 14(1), 1-21.

Carlson, D., \& Perrewe, P. (1999). The role of social support in the stressor-strain relationship: An 
examination of work-family conflict. Journal of Management, 25(4), 513-540.

Clark, S. (2000). Work-family border theory: A new theory of work-life balance. Human Relations, 53(6), 747-770.

Cross, C., \& Linehan, M. (2006). Barriers to advancing female careers in the high-tech sector: Empirical evidence from Ireland. Women in Management Review, 21 (1), 28-39.

Crowley, J. E., \& Kolenikov, S. (2014). Flexible work options and mothers' perceptions of career harm. Sociological Quarterly, 55(1), 168-195.

Ferguson, M., Carlson, D., Kacmar, K. M., \& Halbesleben, J. R. B. (2016). The supportive spouse at work: Does being work-linked help? Journal of Occupational Health Psychology, 21, 37-50.

Frone, M.R., Yardley, J.K., \& Markel, K.S. (1997). Developing and testing an integrative model of the work family interface. Journal of Vocational Behavior, 50, 145-167.

Greenhaus, J., \& Parasuraman, S. (1994). Work-family conflict, social support and well-being. In Davidson, M. and Burke, R. (Eds), Women in Management: Current Research Issues (pp.213229). London: Paul Chapman.

Greenhaus, J.H., Parasuraman, S., Granrose, C., Rabinowitz, S., \& Beutell, N. (1989). Sources of work-family conflict among two-career couples. Journal of Vocational Behavior, 34(2), 133153.

Harlan, A., \& Weiss, C. (1980). Moving up: Women in Managerial Careers, Third Progress Report. Wellesley, MA: Wellesley Center for Research on Women.

Haslam, D., Patrick, P., \& Kirby, J. (2015). Giving voice to working mothers: A consumer informed study to program design for working mothers. Journal of Child \& Family Studies, 24(8), 24632473.

Loscocco, K. (2000). Age integration as a solution to work-family conflict. The Gerontologist, 40(3), 292-300.

Madipelli, S., Sarma V.S.V., \& Chinnappaiah, Y. (2013). Factors causing work-life imbalance among working women-a study on school teachers. The Indian Journal of Industrial Relations, 48(4), 621-633.

Manandhar, S. (2010), Work life balance and Employees' Career Success among different occupational groups, (M. Phil. dissertation), Faculty of Management, Tribhuvan University, Nepal.

Mani, V. (2013).Work-life balance and women professionals. Global Journal of Management and Business Research Interdisciplinary, 13 (5).

Mehta, D. S. (2012).Job satisfaction among teachers. International Journal of Research in Commerce IT \& Management, 2 (4), 77-83.

Perrakis, A., \& Martinez, C. (2012). In pursuit of sustainable leadership: How female academic department chairs with children negotiate personal and professional roles. Advances in Developing Human Resources, 14(2), 205-220.

Rosenbaum, M., \& Cohen, E. (1999). Equalitarian marriages, spousal support, resourcefulness, and psychological distress among Israeli working women. Journal of Vocational Behavior, 54, 102-113.

Shiva, G. (2013). A study on work-family balance and challenges faced by working women. IOSR Journal of Business and Management, 14(5), 1-4.

Shrestha, A. (2009). Role stressors, social support and well being among the dual career couples. (M. Phil. Dissertation), Faculty of Management, Tribhuvan University, Nepal.

Tamang, G. B. (2008). Work-life balance and organizational commitment in hospitality industry in Nepal.(M. Phil. Dissertation), Faculty of Management, Tribhuvan University, Nepal.

Vani, R., \& Nagajoti, V. (2015).A study on personal factors affecting work-life balance of women with reference to IT sector in Chennai. Intercintinental Journal of Human Resource Review, 3(4).

Wallston, R. S., Alagna, S. W., DeVellis, B. M., \& DeVellis, R. E. (1983). Social supports and physical health. Health Psychology, 2, 367-391.

Yadav, R.K., \& Dabhade, N. (2013). Work-life balance amongst the working women in public sector banks-a case study of State Bank of India. International letters of Social \& Humanistic Sciences, 7, 1-22. 